\title{
EDITORIAL
}

\section{Mirando la Revista Enfermería Actual en Costa Rica hacia el futuro.}

\author{
Ana Laura Solano López ${ }^{1}$
}

${ }^{1}$ Doctora en Enfermería, Universidad de Costa Rica, Escuela de Enfermería, Editora en Jefe de la Revista Enfermería Actual en Costa
Rica, San José, Costa Rica. ORCID: 0000-0002-7718-0420

Información del artículo

DOI: 10.15517/revenf.v0i41.47595

La única forma en que la investigación y el análisis científico puedan cumplir su labor social final, el de crear un impacto positivo en la sociedad, es la divulgación, siendo las revistas el principal instrumento de difusión. Las revistas especializadas en enfermería sirven como reservorios de conocimiento disciplinar que esperan ser utilizados para mejorar el cuidado y la identidad profesional, e incidir así en el bienestar de las poblaciones.

Debido a este papel crucial que juegan en la producción del conocimiento científico, considero que una de las responsabilidades más grandes que me han sido conferidas por parte de la Escuela de Enfermería UCR, es la de ser designada como Editora en Jefe de la Revista Enfermería Actual en Costa Rica; publicación pionera en el país que celebra 20 años de ediciones ininterrumpidas, ubicándose en el puesto \#5 de las revistas oficiales de la UCR y que ha ido escalando en indexación, internacionalización y visibilidad.

La labor editorial implica un arduo proceso de arbitraje que tiene como fin decidir, según los criterios de calidad científica y disciplinar, cuál conocimiento se coloca en la palestra. De manera que al asumir este compromiso ético y social, y en conjunto con un excelente consejo editorial, nos hemos dado a la tarea de analizar y reestructurar los procesos editoriales para continuar la evolución de la revista y poder cumplir con las funciones más importantes de la persona editora de una revista en enfermería que son:

1. Mantener la integridad de la revista, la calidad del contenido y la escritura.

2. Proveer una visión, liderazgo, y dirección a la revista y sus lectores.

3. Brindar mentoría y apoyo a los autores y los revisores ${ }^{1}$.

Por lo tanto quiero servirme de este editorial para declarar hacia dónde y cómo queremos dirigirnos.

La Revista Enfermería Actual en Costa Rica se propone ingresar a índices rigurosos, los cuales buscan certificar las publicaciones periódicas según criterios de calidad basados en normativas internacionales ${ }^{2}$, iniciando con Scopus, para luego en avanzar a Medline-Pubmed, CINAHL-EBSCO y Web of Science-JCR. Para este propósito hemos iniciado diversas acciones:

1. Un proceso de revisión y actualización del proceso editorial, incluyendo el objetivo y alcance de la revista, la información para 
autores, las guías para revisores externos, y la escogencia de guías estandarizadas de reporte de investigaciones, así como la actualización del consejo editorial y posteriormente del comité científico internacional.

2. Un proceso de evaluación de pares revisores externos para aumentar su número y asegurar criterios de calidad de revisión.

3. Un proceso de educación continua para los miembros del consejo editorial de la revista.

4. La vinculación formal con otras entidades de la Universidad de Costa Rica, iniciando por la reciente colaboración entre la Revista y el Centro de Investigación en Cuidado de Enfermería y Salud (CICES).

5. El fortalecimiento de las finanzas de la revista, para que podamos expandir los servicios de traducción y no solo publicar en el idioma original, ya sea este español, inglés o portugués.

6. La extensión de la visibilidad e internacionalización de la revista.

7. La renovación de la línea gráfica de la revista.

8. La creación y participación de la revista en actividades de motivación, capacitación, asesoría y mentoría para personas interesadas en la divulgación científica. Desde motivar y guiar a los potenciales autores con o sin experiencia en esta área, así como dar apoyo a las personas pares revisores de nuestra revista para poder asegurar la integridad científica de los artículos seleccionados para publicación.

Esta última acción es de vital importancia ya que aún no tenemos muchos autores y autoras costarricenses publicando en nuestra revista, lo cual es un indicador de la necesidad de capacitación y apoyo en el campo de la investigación en la enfermería de Costa Rica. Y aún más necesaria es la mentoría para que las personas profesionales de enfermería del país puedan desarrollar herramientas de lectura crítica que les permita ser consumidores de nuestra publicaciones, ya que solo así podremos ver el impacto de las mismas en la práctica del cuidado.

La enfermería es una disciplina profesional y un arte en constante evolución, y debe escoger si avanzar en silencio o avanzar dejando huella tangible para que las personas profesionales en enfermería puedan mejorar el cuidado de la salud. Las revistas científicas son una puerta a los nuevos retos, a las posibilidades, a la innovación. Por lo que esperamos ver en el futuro próximo los frutos de estas decisiones editoriales, no solo en el aumento en la lectura y citación de la revista, sino también en la integración del conocimiento a la práctica y su consecuente impacto positivo en la salud de las personas en sus diversos contextos.

\section{Referencias}

1. Kearney $M H$, Freda MC. "Voice of the profession:" Nurse editors as leaders. Nursing Outlook. 2006; 54(5): 263-267. Disponible en: doi:

https://doi.org/10.1016/j.outlook.2006.04.002

2. UCR Index. Clasificación de Índices según su rigurosidad: versión 2.0. Disponible en: https://ucrindex.ucr.ac.cr/?page_id=992 [Consultado el 19 de junio 2021] 